\title{
Model simulations of CFC uptake in North Atlantic Deep Water: Effects of parameterizations and grid resolution
}

\author{
Jens-Olaf Beismann \\ Institut für Meereskunde an der Universität Kiel, Kiel, Germany \\ René Redler \\ C\&C Research Laboratories, NEC Europe Ltd., Sankt Augustin, Germany \\ Received 11 December 2001; revised 26 November 2002; accepted 5 March 2003; published 24 May 2003.
}

[1] A series of numerical experiments with models of the Atlantic Ocean is analyzed with respect to the uptake of CFC-11 and its export from the subpolar gyre with the North Atlantic Deep Water. We discuss the influence of parameterizations for air-sea gas exchange and subgrid-scale processes on the rate of CFC-11 that enters the North Atlantic Ocean and its dependence on horizontal grid spacing in models from medium $\left(4 / 3^{\circ}\right)$ to eddy-permitting $\left(1 / 3^{\circ}\right)$ horizontal resolution. Model results are compared with observational estimates of tracer inventories in order to evaluate to what degree the simulations capture realistic CFC distributions. While higher resolution is needed to model details of the CFC distribution, for example, in the Deep Western Boundary Current, the medium resolution models are able to simulate quantitatively satisfying CFC inventories in different water masses. Nevertheless, the inventories derived from the medium-resolution experiments show a critical dependence on details of the parameterization of the mixing effect of mesoscale eddies and on the representation of bottom boundary layer processes. The numerical representation of eddy activity turns out to be of crucial importance in order to obtain modeled CFC inventories in agreement with observed values, which can be achieved either by carefully choosing the mixing parameterization or by applying higher horizontal resolution. The ratio of CFC-11 being exported southward from the subpolar North Atlantic to the total CFC-11 inventory in NADW does not vary significantly over the suite of model experiments. INDEX TERMS: 4255 Oceanography: General: Numerical modeling; 4283 Oceanography: General: Water masses; 4808 Oceanography: Biological and Chemical: Chemical tracers; KEYWORDS: numerical modeling, North Atlantic Deep Water, subpolar North Atlantic, chlorofluorocarbons, mixing parameterization, high-resolution simulations

Citation: Beismann, J.-O., and R. Redler, Model simulations of CFC uptake in North Atlantic Deep Water: Effects of parameterizations and grid resolution, J. Geophys. Res., 108(C5), 3159, doi:10.1029/2001JC001253, 2003.

\section{Introduction}

[2] The North Atlantic Deep Water (NADW) with its source water masses is a major component of the global oceanic thermohaline circulation. Understanding the formation processes of the different water mass components of NADW and the uptake of anthropogenic $\mathrm{CO}_{2}$ going along with this is still a key issue when investigating the global circulation and the coupled ocean-atmosphere climate system. As often pointed out in the literature, these processes take place on a relatively small scale compared to the basinwide circulation, and transport paths of newly formed water masses from the Arctic Ocean into the North Atlantic are winding through narrow passages in the Greenland-IcelandScotland ridge system [Dickson and Brown, 1994; Saunders, 1996].
[3] Furthermore, NADW formation rates turn out to be highly variable in time from interdecadal timescales down to days. Prominent examples of these are the interdecadal variability of Labrador Sea convection [see, e.g., Dickson et al., 1996], the Denmark Strait Overflow [Dickson and Brown, 1994] or the Iceland Faeroe Overflow [Saunders, 1996], which connect the Arctic Ocean with the North Atlantic.

[4] Because of the sparse coverage in space and time of field measurements the question how these processes are related to the climate system and how they interact with each other cannot be answered from observations alone. Numerical models are valuable and widely accepted tools to gain deeper understanding and insight into the natural phenomena. In order to simulate the global circulation with a certain degree of realism, sufficiently high resolution in both space and time is required.

[5] Tracing the uptake and redistribution of chlorofluorocarbons (CFC) provides a powerful tool to study ocean circulation and the mechanisms of water mass formation, 
both in the real ocean and in numerical simulations [e.g., Rhein, 1994; England, 1995]. With respect to model results the intercomparison of field measurements and modeled CFC distributions is a useful means for assessing the models' capability of representing physical processes in key regions of water mass formation. CFCs thus help to determine whether a model correctly simulates, for example, NADW formation rates, outflow pathways (e.g., southward propagation with the Deep Western Boundary Current (DWBC)), and current speeds [e.g., England and Holloway, 1998; Heinze et al., 1998].

[6] CFCs have been frequently used for this purpose in the recent literature (see England and Maier-Reimer [2001] for a review], mostly with models of rather coarse horizontal resolution of about $2^{\circ}$ to $4^{\circ}$ in latitude and longitude. In comparing results of these models with observations, the question arises which aspects of the model solutions can be assumed to be fairly independent of model resolution and/or configuration, and which features are likely to change with future generations of models of higher resolution.

[7] CFCs are particularly useful when addressing the problem of simulating the deep overflow in the North Atlantic Ocean and its southward path on decadal to interdecadal timescales. Conventional hydrographic tracers such as temperature and salinity offer only limited information on details of the water mass formation processes, such as the depth of rapid ventilation associated with surface mixing [England and Maier-Reimer, 2001], the accuracy of the model in simulating the southward transport of deep water masses in the DWBC or the timescale of ventilation processes.

[8] At the present time, numerical ocean models used for long term climate studies on a global scale are limited in realistically simulating the exchange processes between the Arctic and the North Atlantic Ocean due to their coarse resolution of 100 to $200 \mathrm{~km}$ in subpolar latitudes. Some of these models lack this interaction completely. Formation of NADW is shifted southward of the location of the above-mentioned passages [Rahmstorf et al., 1996], or it is restricted to the Arctic Ocean north of $70^{\circ} \mathrm{N}$ [Weaver and Hughes, 1996]. Since the throughflow of DSOW is subject to hydraulic control [Käse and Oschlies, 2000], the sill system may restrict the interaction between water mass formation in the Arctic and the response of the thermohaline circulation. Even with the next generation of ocean models for climate studies we will not be able to explicitly resolve such phenomena.

[9] Among others, England and Maier-Reimer [2001] state that improvements concerning the representation in downslope flow in z-level models can be achieved when employing a bottom boundary layer (BBL) scheme. With respect to $\mathrm{CFCs}$, their findings are based on preliminary results by Redler and Dengg [1999] which are revisited and extended in more detail in this study.

[10] Another issue of very coarse resolution models addresses the high diffusivity and its impact on water mass propagation and distribution. Ideally, the subgrid-scale parameterization employed by any numerical model should not affect the propagation rate of a signal when compared with a higher resolution model and field measurements.
[11] A series of model studies on the impact of various mixing schemes has been published by England and Hirst [1997] and England and Holloway [1998], who found that the NADW production was problematic in all of their simulations unless artificial modifications of the surface forcing were introduced. Because of the coarse horizontal resolution they employed, their results are strongly influenced by the poor representation of key processes for deep water formation and tracer uptake: Convection in the Labrador Sea is confined to the upper $250 \mathrm{~m}$ only (possibly also a result of the forcing fluxes applied to their model), the influence of dense overflows across the Greenland-Iceland-Scotland ridge system is negligible compared with the unrealistic deep water formation southeast of Greenland, and the southward propagation of the CFC signal with the DWBC is generally much too broad and diffusive, leading to an underestimation of ventilation rates. Because of the long integration times required for their experiments, they were not able to compare their solutions to simulations with higher resolution. While some of their numerical experiments show reasonable production rates and southward transports of NADW, this must go along with low velocities at individual grid points located in the DWBC region: The DWBC is hardly resolved with coarse resolution models, and individual velocities represent an average over the whole volume of the respective grid box which then has to represent both a core of the DWBC and weak currents further offshore. One of the logical consequences is an underestimation of ventilation rates of water masses directly influenced by NADW.

[12] Dutay et al. [2002] compared CFC simulations from the 13 global ocean models used in the Ocean Carbon cycle Model Intercomparison Project (OCMIP) global ocean models to observations. One of their conclusions was that all prognostic models underestimated the CFC uptake in NADW. The detailed comparison showed that different models have different strengths and weaknesses and that none of them was able to reproduce the observations exactly. A systematic analysis of the model deficiencies was very difficult in this study because of the great number of differences (in grid resolution, numerical schemes, parameterizations, forcing, etc.) among the models that influenced the CFC simulations. The present study can be regarded as an extension of this work by using one state-of-the-art ocean model to systematically explore the qualitative and quantitative influence of factors governing the model physics on a CFC simulation.

[13] Estimating the rate at which anthropogenic $\mathrm{CO}_{2}$ enters and penetrates the ocean is one of the key issues for understanding and predicting the behavior of the climate system with coupled ocean-atmosphere models. Körtzinger et al. [1999] have shown that a close correlation between anthropogenic $\mathrm{CO}_{2}$ and CFC-11 exists in the subpolar North Atlantic and that CFC concentrations thus could serve as proxy data for anthropogenic $\mathrm{CO}_{2}$. In contrast to anthropogenic $\mathrm{CO}_{2}, \mathrm{CFC}$ are easier to include in numerical models because of their chemical inertness and well known time series of spatially nearly homogenous atmospheric concentrations over the last decades. Detailed knowledge about how the representation of gas uptake affects calcu- 
lated inventories are crucial for a correct interpretation of scenarios addressing the uptake of anthropogenic $\mathrm{CO}_{2}$. Previous authors [e.g., England et al., 1994; England and Maier-Reimer, 2001] have explored the sensitivity of the simulated air-sea gas fluxes to different formulations of the piston velocity and found errors of 5 to $15 \%$ associated with uncertainties in the piston velocity, but since they restricted themselves mainly to the comparison of tracer concentrations on certain ocean sections, very little can be found in the literature concerning the influence of gas flux parameterizations on total oceanic inventories of dissolved tracers. Furthermore, the numerical models used in the above mentioned studies were of rather coarse horizontal resolution (typically of the order of $4^{\circ}$ ), leading to large uncertainties in the representation of key processes governing tracer uptake like convection in subpolar regions. It is thus possible that these findings might change when models with finer grid spacing are employed.

[14] Estimates of oceanic tracer $\left(\mathrm{CFC}, \mathrm{CO}_{2}\right)$ inventories are difficult to derive observationally because a number of assumptions have to be made when calculating three-dimensional distributions from hydrographic sections. The nonsynopticity of hydrographic observations and the sparse data distribution in time makes it necessary to normalize the data to a common year. Only recently, estimates of North Atlantic CFC inventories based on data from 1986 to 1997 have become available [Smethie and Fine, 2001; Rhein et al., 2002]. We will put special emphasis on comparing simulated inventories to these observations and on identifying the model-inherent factors that influence the inventories.

[15] Having introduced the experimental design in section 2 we are going to present results of our studies in section 3. In a series of sensitivity studies we revisit and extend the work of England and Hirst [1997] and England and Holloway [1998] using numerical models of significantly higher resolution and with more recent parameterizations of certain processes. In section 4, we discuss our results and draw some conclusions with respect to experiments addressing the ocean's role in a climate system with increasing atmospheric anthropogenic $\mathrm{CO}_{2}$ concentrations.

\section{Experimental Design}

[16] The numerical model used in this study is an enhanced version of the GFDL MOM2.1 code [Pacanowski, 1995], developed as part of the Family of Linked Atlantic Model Experiments (FLAME), a framework for modeling projects that study the physics and biogeochemistry of the Atlantic Ocean [Dengg et al., 1999] (see also http://www.ifm.uni-kiel. $\mathrm{de} / \mathrm{fb} / \mathrm{fb} 1 / \mathrm{tm} / \mathrm{research} /$ FLAME/index.html). The model area under consideration covers the Atlantic between $70^{\circ} \mathrm{N}$ and $70^{\circ} \mathrm{S}$, with the Southern Ocean being restricted to the area between Drake Passage and $30^{\circ} \mathrm{E}$ for the coarse resolution integration [cf. Eden and Willebrand, 2001]. The eddypermitting model discussed in this study spans the North Atlantic between $70^{\circ} \mathrm{N}$ and $18^{\circ} \mathrm{S}$ [cf. Böning et al., 2003].

\subsection{Basic Model Setup}

[17] The model topography was calculated from a data set with 5' resolution provided by the National Geophysical Data Center [1988]. Except for removal of single grid point holes or spikes, no smoothing was applied. Following
Willebrand et al. [2001], the resulting topography has been carefully examined with respect to the representation of several important passages like, for example, the Faeroe Bank Channel and the Denmark Strait. The width and depth of these passages have been modified in order to allow for advective transport down to the original sill depth.

[18] The two model versions both use a Mercator grid in the horizontal, but of different resolution. For the eddypermitting model, we have adopted a horizontal (latitude $\times$ longitude) grid spacing of $1 / 3^{\circ} \cos \phi \times 1 / 3^{\circ}$ with $\phi$ being latitude, leading to an average horizontal resolution of $28 \mathrm{~km}$; for the coarser resolution version, we applied $4 / 3^{\circ}$ $\cos \phi \times 4 / 3^{\circ}$. There are 45 nonequidistant levels in the vertical in both configurations, with a spacing of $10 \mathrm{~m}$ in the uppermost level and a smooth increase to $250 \mathrm{~m}$ at $2500 \mathrm{~m}$ depth. Below $2500 \mathrm{~m}$ the vertical grid box thickness is a constant $250 \mathrm{~m}$ up to an maximum depth of $5500 \mathrm{~m}$.

[19] Open boundary conditions are implemented following the approach of Stevens [1991] along $70^{\circ} \mathrm{W}$ and $30^{\circ} \mathrm{E}$ in the $4 / 3^{\circ}$ experiments and at $18^{\circ} \mathrm{S}$ in the $1 / 3^{\circ}$ run. The northern boundary is closed in both model configurations. To include the effect of water mass formation in the Greenland Sea, a restoring of potential temperature and salinity to climatological data is applied in the 10 northernmost latitude bands in the $1 / 3^{\circ}$ run and in a restoring area similar to the DYNAMO configuration in the $4 / 3^{\circ}$ experiment. The data used for this restoring are similar to the data used in the DYNAMO experiments [Willebrand et al., 2001] and are applied for all our case studies. A restoring to CFC was not necessary since both models are able to produce realistic $\mathrm{CFC}$ concentrations in the overflow water masses without artificial restoring.

[20] For horizontal diffusion of tracers (potential temperature $(\Theta)$, salinity $(\mathrm{S})$, and CFCs) we use mixing along isopycnal surfaces following Redi [1982] and Cox [1987]. Most of our experiments employ an eddy induced tracer advection parameterization according to Gent and McWilliams [1990] (hereinafter referred to as GM90), in some cases with horizontal background diffusion. Both coefficients, isopycnal diffusivity and thickness diffusivity, are set to $2 \cdot 10^{7} \mathrm{~cm}^{2} / \mathrm{s}\left(2 \cdot 10^{6} \mathrm{~cm}^{2} / \mathrm{s}\right.$ in the eddy-permitting experiment), decaying with depth to $0.5 \cdot 10^{7} \mathrm{~cm}^{2} / \mathrm{s}(0.5$. $10^{6} \mathrm{~cm}^{2} / \mathrm{s}$ ) below $4000 \mathrm{~m}$. Along boundaries the coefficients are set to zero. Constant coefficients for horizontal viscosity of $10^{8} \cdot \cos \phi \mathrm{cm}^{2} / \mathrm{s}\left(10^{7} \cdot \cos \phi \mathrm{cm}^{2} / \mathrm{s}\right)$ are chosen. See Table 1 for the setup of the individual experiments. The

Table 1. List of Experiments ${ }^{\mathrm{a}}$

\begin{tabular}{|c|c|c|c|c|c|c|}
\hline Experiment & $\vec{\tau}$ & $\mathrm{q}$ & $\tau_{C F C}$ & $\mathrm{Ah}_{\text {back }}$ & GM90 & $\mathrm{BBL}$ \\
\hline BR1 & NCEP & NCEP & $7.43 \mathrm{~d}$ & 0 & yes & yes \\
\hline BR2 & NCEP & NCEP & $2 \mathrm{~d}$ & 0 & yes & yes \\
\hline BR3 & NCEP & NCEP & var & 0 & yes & yes \\
\hline BR4 & NCEP & NCEP & $2 \mathrm{~d}$ & 0 & yes & no \\
\hline BR5 & NCEP & NCEP & $2 d$ & $2 \times 10^{6} \mathrm{~cm}^{2} / \mathrm{s}$ & no & yes \\
\hline BR6 & NCEP & NCEP & $2 d$ & 0 & $\begin{array}{c}\text { yes } \\
\text { (red. coeff.) }\end{array}$ & yes \\
\hline BR7 & clim & NCEP & $7.43 \mathrm{~d}$ & $10^{6} \mathrm{~cm}^{2} / \mathrm{s}$ & yes & yes \\
\hline BR7h & clim & NCEP & $7.43 \mathrm{~d}$ & $2 \times 10^{5} \mathrm{~cm}^{2} / \mathrm{s}$ & yes & yes \\
\hline
\end{tabular}

${ }^{a}$ All experiments have been carried out with the $4 / 3^{\circ}$ model, except for the $1 / 3^{\circ}$ case BR7h. "NCEP" indicates that monthly varying forcing anomalies for the years 1958 to 1996 added to the ECMWF climatology have been used, whereas "clim" indicates that climatological monthly mean ECMWF forcing has been used. 
time step applied to our models is $3600 \mathrm{~s}$ for the $4 / 3^{\circ}$ model and $1200 \mathrm{~s}$ for the higher-resolution run.

[21] We use the bottom boundary layer (BBL) scheme proposed by Beckmann and Döscher [1997], which, in combination with isopycnal mixing of tracers, maintains the signal of dense water overflowing the Greenland-Iceland-Scotland Ridge system. This leads to overflow signals that follow the deep western boundary currents in the overflow regions, rather than getting mixed with the surroundings when they cross the ridges [Döscher and Beckmann, 2000].

[22] To parameterize vertical diffusion, we use Laplacian mixing following the approach of Cummins et al. [1990]. Parameters have been chosen to result in stability dependent mixing coefficients ranging from $0.1 \mathrm{~cm}^{2} / \mathrm{s}$ to $4.0 \mathrm{~cm}^{2} / \mathrm{s}$. For vertical viscosity, we use constant coefficients of $10 \mathrm{~cm}^{2} / \mathrm{s}$. If the stratification of the water column is unstable, the effect of free convective overturning is parameterized by vertically exchanging water mass properties among unstably stratified boxes. Wind forced deepening of the surface mixed layer is included by a simplified mixed layer model following Sterl and Kattenberg [1994].

[23] All experiments have been forced by monthly mean atmospheric fluxes of wind stress and heat, whereas the freshwater forcing is parameterized by a relaxation to surface salinity data. Net heat flux and wind stress data are based on a 3-year climatology of ECMWF analyses (1986 to 1988) [Barnier et al., 1995; Siefridt, 1994]. The heat flux included also a relaxation to climatological sea surface temperature in the formulation given by Haney [1971]. For the relaxation to surface salinity we use a combination of the climatologies given by Boyer and Levitus [1997] and Levitus et al. [1994]. The seasonal cycle contained in the monthly mean $1 \times 1^{\circ}$ climatology of Levitus et al. [1994] was extracted and carefully applied to the annual mean $1 / 4^{\circ}$ $\times 1 / 4^{\circ}$ climatology of [Boyer and Levitus, 1997], in order to obtain both high-temporal and spatial resolution.

[24] In order to take into account the low-frequency atmospheric variability during the CFC simulation period (compare section 2.2), monthly mean anomalies (with respect to climatological monthly means over the period 1958-1996) of net heat flux and wind stress have been extracted from the NCEP/NCAR reanalysis data [Kalnay et al., 1996] for the period 1958 to 1996. These anomalies have then been added to the ECMWF-based climatological forcing described above in most of our experiments (see columns 2 and 3 of Table 1). A detailed description of this superposition of forcing fluxes is given by Eden and Willebrand [2001]. No explicit ice model is taken into account; instead we switch off surface forcing for heat and salt as well as passive tracer fluxes (see section 2.2) during cooling phases if the sea surface temperature (SST) is below freezing point.

[25] All individual experiments are initialized with January $\Theta$ and S fields and are spun up from a state of rest (spin up not listed in Table 1) for an integration period of 20 model years, forced with the ECMWF climatology described above. This integration time is sufficient for the model to reach a dynamical quasi-equilibrium [Willebrand et al., 2001].

\subsection{Uptake of CFC}

[26] Air-sea fluxes of CFC-11 are implemented by a relaxation of surface concentrations to saturation in the uppermost level $(10 \mathrm{~m})$. Surface saturation is calculated using atmospheric CFC concentrations for the Northern and Southern Hemisphere (by courtesy of Stephen Walker, 1998). Data have been interpolated linearly across the equator between $10^{\circ} \mathrm{N}$ and $10^{\circ} \mathrm{S}$. The CFC simulations start with atmospheric CFC concentrations in 1950 and continue to 1996.

[27] In contrast to England and Holloway [1998], we take the model predicted $\Theta$ and S surface fields to compute the $\Theta$-S dependent solubility of CFC-11 instead of an observed seasonal $\Theta-S$ climatology. Therefore, in our model, actual surface level CFC concentrations are not only subject to changes of patterns of convection and vertical velocity as in the work of England and Holloway [1998], but they will vary directly due to changes in the simulated $\Theta-S$ fields in the different model cases. In the ocean interior, the spreading of passive tracers is governed by the same advection and diffusion operators as temperature and salinity.

[28] In a first attempt, we choose a relaxation time corresponding to a constant piston velocity of $\mathrm{k}_{c}=5.6 \mathrm{~cm} / \mathrm{h}$. This value has been derived by Broecker et al. [1980] from observations of the saturation process. Our choice corresponds to a restoring timescale for CFCs in the uppermost level $(\Delta z=10 \mathrm{~m})$ of 7.43 days (see column 4 of Table 1$)$. Similar to $\Theta$ and S, no surface restoring of CFCs is applied at grid points where the model SST is below freezing point. This leads us to a piston velocity for CFCs in the form

$$
k_{C F C}=k_{c}(1-R),
$$

similar to experiment CF2 of England et al. [1994]. In contrast to England et al. [1994], we do not take into account partial ice cover of the individual grid boxes. Because of the higher horizontal resolution of our model, we expect this effect to be negligible. Thus, in our case, $\mathrm{R}$ obtains values of either 0 or 1 .

[29] To further improve the representation of the exchange process of CFC between ocean and atmosphere in our model, we adopt a complete parameterization of piston velocity as suggested by Wanninkhof [1992] leading to (compare to experiment CF4 of England et al. [1994])

$$
k_{C F C}=k_{0} u^{2}(1-\mathrm{R}) /\left(\frac{\mu}{D_{C F C}}\right)^{1 / 2} \text {. }
$$

Here $u$ represents wind speed, $\mu$ is the viscosity of seawater, $D_{C F C}$ the diffusion constant of CFC and $k_{0}$ is a constant (7.964) derived from bomb-produced radio carbon invasion rates into the ocean.

[30] Using the NCEP/NCAR wind speed data, we calculated climatological monthly mean piston velocities for the Atlantic Ocean both with the above formula and the recent parameterization by Wanninkhof and McGillis [1999]. The mean value for the North Atlantic north of $35^{\circ} \mathrm{N}$ for the months October through March is $21.08 \mathrm{~cm} / \mathrm{h}$ for CFC-11 (corresponding to a restoring timescale of 1.98 days in our model configuration). The ventilation of the deep ocean and the associated gas uptake in the North Atlantic being the focus of this study, this choice of averaging intervals gives a value that is representative for the main region and period of CFC uptake. In order to assess the effect of this new restoring timescale, we first conduct an experiment (experiment BR2) using a constant restoring timescale of 2 days (that is applied 
everywhere in the model domain and at all points in time) before proceeding to an experiment with a temporally and spatially varying CFC restoring as given by equation (2) (experiment BR3). For a more detailed discussion of the choice of the formulation of the gas flux across the air-sea interface the reader is referred to England et al. [1994].

\section{CFC Uptake and Inventories}

\subsection{Model-Data Comparison of a CFC Section}

[31] In order to evaluate the performance of our model with respect to its ability to reproduce observed CFC distributions, we briefly present a comparison between tracer data from a meridional hydrographic section in the eastern North Atlantic as observed in July/August 1993 [Doney et al., 1998] (Figure 1a) and the same section from our model experiments BR3 (Figure 1b) and BR6 (Figure 1c). The simulated sections compare fairly well with the observations, especially in the upper tropical and subpolar North Atlantic where absolute concentrations and penetration depths are realistically reproduced. In the subtropics, however, model deficiencies are clearly visible: Penetration depths are underestimated in the upper $800 \mathrm{~m}$, and the simulations exhibit an intermediate $\mathrm{CFC}$ minimum at around $1000 \mathrm{~m}$ that is not present in the observations. These problems are related to the fact that our model tends to underestimate the ventilation rate of subtropical mode water [Czeschel, 2000]. At a depth of about $1600 \mathrm{~m}$, both model cases show the CFC maximum associated to LSW that propagates too far to the south in the eastern basin (compare to section 3.4). Concentrations in the deep subpolar ocean agree rather well with the observed pattern in both cases. At the equator, the upper and lower cores of NADW are characterized by CFC maxima at 1500 and $4000 \mathrm{~m}$ in the observations. Because of deficiencies in the simulated equatorial dynamics, the tracer signals have not reached the eastern basin of the equatorial Atlantic. The misrepresentation of the eastward tracer tongue on the equator has been discussed in detail by Kröger [2001].

[32] Differences in the two simulated sections are mainly due to the reduction of the thickness diffusivity coefficient in BR6. The diffusive southward propagation of LSW has been reduced significantly in BR6. These findings are confirmed by model case BR7h where the diffusive signal is further reduced (compare to section 3.4).

[33] Our simulations are in many aspects similar to the OCMIP models evaluated by Dutay et al. [2002, cf. their Figure 5]. It is mainly the use of the BBL parameterization and the higher horizontal resolution that distinguishes our model from those experiments. This comparison thus shows that our simulations are at least comparable to the OCMIP models, as far as the reproduction of observed tracer distributions is concerned (this is also true for other sections in the North Atlantic which are not shown here). Our model thus represents an appropriate basis to study the effect of various parameterizations of physical processes on tracer simulations.

\subsection{Sensitivity to Air-Sea Gas Exchange Parameterization}

[34] We start our investigation with a set of experiments that assess the role of the air-sea gas flux parameterization.
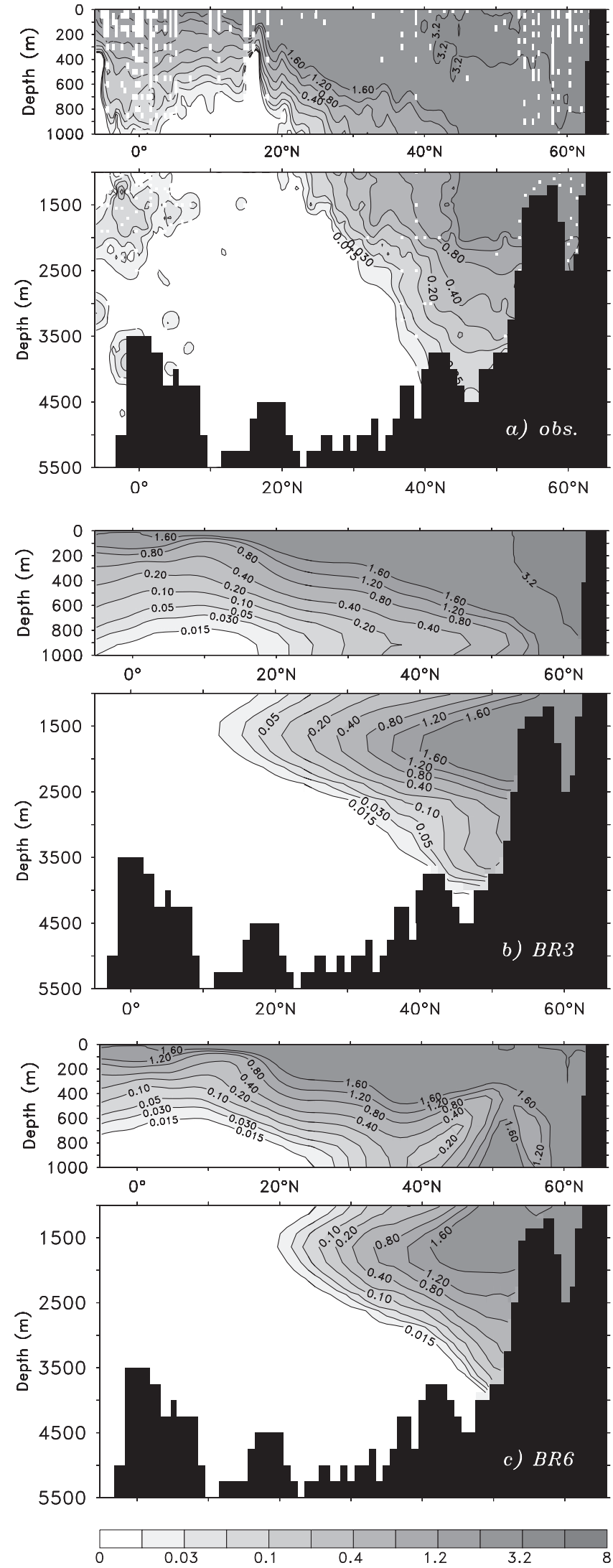

Figure 1. CFC-11 along a meridional section at nominally $20^{\circ} \mathrm{W}$ in the North Atlantic in July/August 1993 from (a) observations [Doney et al., 1998] and our model cases (b) BR3 and (c) BR6 (in pmol/L, $1 \mathrm{pmol}=10^{-12} \mathrm{~mol}$ ). 

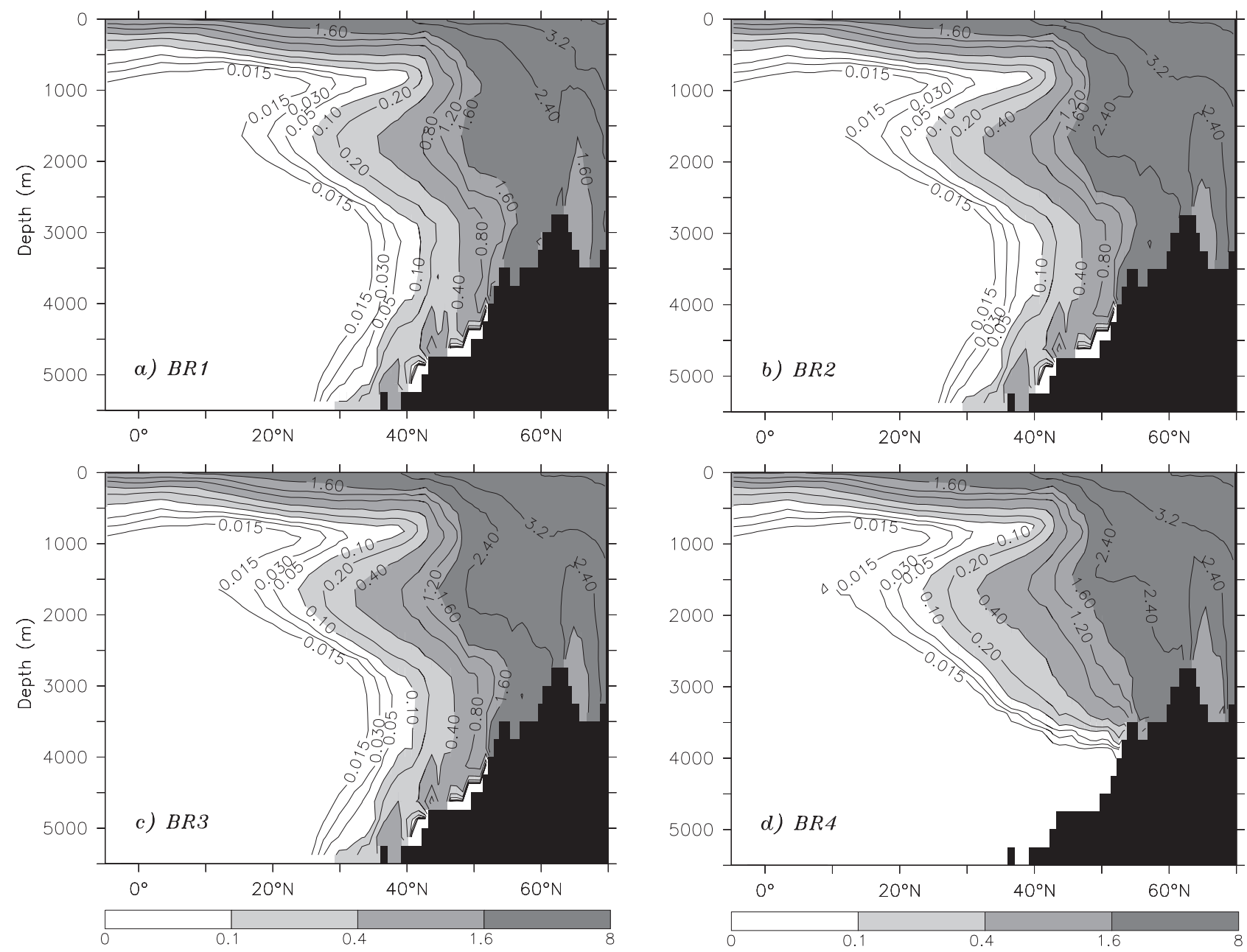

Figure 2. Annual mean (1990) zonally averaged CFC-11 concentration in the North Atlantic (in pmol/1), for experiment (a) BR1, (b) BR2, (c) BR3, and (d) BR4.

As shown in Table 1, two experiments use constant piston velocities (BR1, BR2) while the third experiment (BR3) uses the more sophisticated approach of a wind speed dependent gas transfer velocity.

[35] Figure 2 shows the zonally averaged CFC-11 concentrations in the North Atlantic for the experiments BR1, BR2, BR3, and BR4 for 1990 (annual means). We use zonally averaged concentrations to take into account the integrated effect of a change in the gas uptake parameterization over the North Atlantic. In all experiments highest concentrations are found in subpolar and polar latitudes where the solubility for CFCs is highest. Strong vertical mixing during late winter leads to high CFC concentrations throughout the whole water column in this region. Between 1000 and $2500 \mathrm{~m}$, the CFC signal associated with the upper NADW spreads southward to about $15^{\circ} \mathrm{N}$. Between 3000 and $4000 \mathrm{~m}$ our model shows the intermediate CFC minimum of the Iceland-Scotland Overflow Water (ISOW), whereas the Denmark Strait Overflow Water (DSOW) is characterized by a local maximum close to the bottom. This CFC distribution is in general agreement with the results of Dutay et al. [2002], with the main difference being that our model is able to reproduce the observed CFC signal in the DSOW because of the use of the bottom boundary layer parameterization by Beckmann and Döscher [1997] (discussed below).

[36] As can be expected, the higher piston velocity used in experiment BR2 (Figure 2b) leads to higher CFC concentrations in the subpolar and polar Atlantic due to an increased gas uptake by surface waters. Vertical convection in the regions of water mass formation transmits this increase to the NADW components, as can be seen by the farther penetration of the upper North Atlantic Deep Water (uNADW) $\mathrm{CFC}$ signal $\left(11^{\circ} \mathrm{N}\right.$ instead of $\left.15^{\circ} \mathrm{N}\right)$ in comparison to experiment BR1 (Figure 2a). As for the uNADW, the model DSOW is influenced by the increased CFC uptake in polar regions and shows higher $\mathrm{CFC}$ concentrations close to the ocean floor between 40 and $60^{\circ} \mathrm{N}$.

[37] The latitudinal position of the local minimum at a depth of $1000 \mathrm{~m}$ does not change from model cases BR1 to BR2, indicating that waters at this depth are not ventilated from the subpolar North Atlantic. On the other hand, the second local minimum between 3000 and $4000 \mathrm{~m}$ shows a slight increase of CFC concentrations at about $40^{\circ} \mathrm{N}$. This depth range corresponds to the ISOW in our model which, because of its path all around the Iceland and Irminger basins, has the longest ventilation timescale at this latitude and therefore only begins to show effects of the increased uptake. 


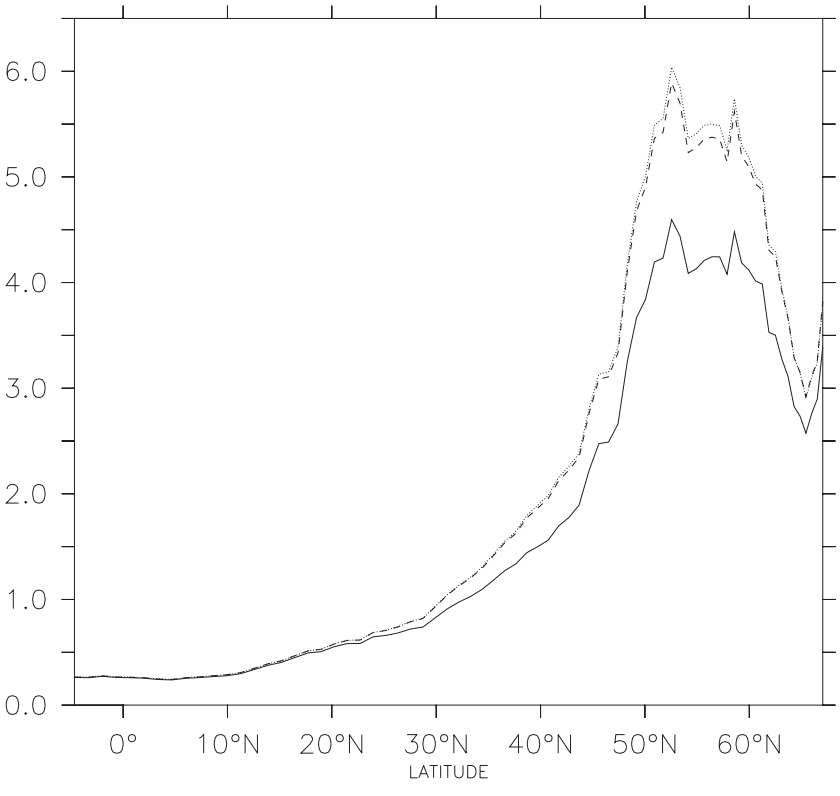

Figure 3. Annual mean (1990) zonally averaged CFC-11 inventory in the North Atlantic (in $10^{3} \mathrm{pmol} / \mathrm{m}^{2}$ ). Solid line: experiment BR1; dashed line: experiment BR2; dotted line: experiment BR3.

[38] The zonally averaged CFC inventory, i.e., the vertically integrated CFC concentration (Figure 3), shows that the effect of the increased piston velocity is strongest north of about $40^{\circ} \mathrm{N}$. The peak value at $53^{\circ} \mathrm{N}$ is higher by about $33 \%$ in BR2. When integrated over the North Atlantic between the equator and $70^{\circ} \mathrm{N}$, the total CFC inventory amounts to 59.2 million moles for experiment BR1 and 71.1 million moles for BR2, a difference of $20 \%$.

[39] There are no significant differences in the CFC concentrations of the tropical and subtropical surface and thermocline waters. This is an indication that these water masses are already CFC saturated and cannot react to an increase in the air-sea gas transfer velocity.

[40] A comparison of experiments BR2 (Figure 2b) and BR3 (Figure 2c) shows that the use of a fully wind speed dependent gas transfer parameterization in our model gives virtually no differences in the zonally averaged concentrations. The highest differences in the CFC inventory can be found at $52^{\circ} \mathrm{N}$ where the inventory in case BR3 is $2.4 \%$ higher than in BR2. North of about $62^{\circ} \mathrm{N}$ as well as in tropical and subtropical latitudes the differences between BR3 and BR2 are close to zero. The total CFC inventory of the North Atlantic is 72.0 million moles for experiment BR3 compared to 71.1 million moles in BR2. Integrated over the whole Atlantic Ocean, the difference between experiments BR2 and BR3 is negligible: 256.4 million moles for BR2 and 256.3 million moles for BR3. We can therefore state that at least at non-eddy permitting resolution a constant gas transfer velocity is an appropriate choice for the parameterization of air-sea gas exchange, provided that the chosen value is representative for the region and the period of maximum CFC uptake. We note that small regional differences (on the order of $5 \%$ of the absolute CFC concentration) between experi- ments BR2 and BR3 occur at the end of winter in the surface mixed layer of the high latitudes.

\subsection{Representation of the Bottom Boundary Layer}

[41] As stated above and shown by Döscher and Beckmann [2000] and Dengg et al. [1999], the implementation of a bottom boundary layer (BBL) parameterization represents a major improvement for level coordinate ocean models at horizontal and vertical resolutions comparable to our configuration. Without a BBL, these models tend to create spurious mixing in the areas where dense water masses overflow shallow sills like the Denmark Strait or the Iceland-Scotland ridge system. The BBL parameterization in combination with isopycnal tracer mixing allows conservation of the density signal of the overflow waters, which is a necessary requirement for a realistic representation of the vertical water mass structure in the subpolar North Atlantic.

[42] In order to analyze the effect of the BBL parameterization on the $\mathrm{CFC}$ uptake and redistribution, we conducted an experiment similar to BR2 but without the BBL (BR4). We then calculated CFC-11 inventories for 1990 for the region between $42^{\circ} \mathrm{N}$ and $65^{\circ} \mathrm{N}$ in each of the NADW components. This gives an indication of the net effect of the BBL with regard to the model representation of the uptake of anthropogenic trace gases in the subpolar North Atlantic and allows us to compare our results to the observational estimates by Smethie and Fine [2001]. Table 2 shows the resulting inventories from our experiments as well as the observational data. (The bounding isopycnal surfaces of the three water masses have been chosen according to the simulated water mass properties of our models; thus, they differ slightly from the observed upper and lower boundaries.)

[43] The positive influence of the BBL parameterization is clearly visible in the densest NADW component (DSOW): While most of the CFC burden is carried by LSW and ISOW (with a large overestimation of the ISOW inventory in comparison to observations) in BR4, the introduction of the BBL scheme in BR2 leads to a reorganization of the vertical distribution, with LSW now holding approximately two thirds of the total inventory while the remainder is split between DSOW and ISOW. The total NADW inventory is comparable in both cases and is about $25 \%$ higher than the estimate of $19.43 \times 10^{6}$ moles derived from nonsynoptic observations by Smethie and Fine [2001], but only when the BBL is switched on the model is able to represent the distribution of the total inventory on the NADW components as observed (LSW 64\%, ISOW 20\%, and DSOW 16\%). The effect of the missing BBL in experiment BR4 is also visible in Figure $2 \mathrm{~d}$. CFC penetration is limited to a depth of slightly less than $4000 \mathrm{~m}$, and there is no signature of the southward

Table 2. CFC-11 Inventories in the Subpolar Region $\left(42^{\circ} \mathrm{N}-\right.$ $65^{\circ} \mathrm{N}$; in $10^{6}$ moles) in $1990^{\mathrm{a}}$

\begin{tabular}{lrrrrrrr}
\hline & BR2 & \multicolumn{1}{c}{ BR4 } & BR5 & BR6 & BR7 & BR7h & Observed \\
\hline LSW & 15.36 & 9.50 & 14.86 & 11.13 & 11.49 & 6.01 & 12.5 \\
ISOW & 4.92 & 14.07 & 8.52 & 4.12 & 4.06 & 3.08 & 3.8 \\
DSOW & 3.67 & 0.77 & 0.92 & 2.90 & 2.71 & 2.55 & 3.1 \\
Total NADW & 23.95 & 24.35 & 24.30 & 18.15 & 18.26 & 11.64 & 19.4 \\
\hline
\end{tabular}

${ }^{\mathrm{a}}$ For comparison, the observational estimates by Smethie and Fine [2001] are also shown. 
DSOW propagation in the tracer distribution. On the other hand, CFC concentrations between 3000 and $4000 \mathrm{~m}$ and between $32^{\circ} \mathrm{N}$ and $42^{\circ} \mathrm{N}$ are higher in BR4 than in the experiments with the $\mathrm{BBL}$ parameterization.

[44] In BR4, the CFC signal entering the Atlantic Ocean through Denmark Strait is mixed into the ISOW density range. Because of this spurious mixing of DSOW, the stratification of the water underlying the LSW is enhanced, thereby reducing the maximum convection depth in the Labrador Sea and the volume of LSW, which leads to a smaller CFC inventory in the LSW density class. The DSOW inventory of $3.67 \times 10^{6}$ moles in the BBL case is in good agreement with observations [Smethie and Fine, 2001]. Since our simulated volume transport of dense water through Denmark Strait is comparable to observed values [Girton et al., 2001], this gives some insight into the water mass conversion in the northern restoring zone used in our model: Although CFC-11 can only enter the model domain through the surface, the processes that take place in the restoring zone are able to mix it down through the whole water column and to provide the DSOW entering the subpolar Atlantic through Denmark Strait with an appropriate CFC concentration.

\subsection{Numerical Representation of Eddy Activity \\ 3.4.1. Parameterizations}

[45] Numerical models that do not resolve mesoscale eddies have to rely on some parameterization to represent the mixing effect of eddies on tracer distributions. We will discuss the CFC-11 distribution in UNADW from a series of experiments (BR2, BR5 and BR6) with the $4 / 3^{\circ}$ configuration that employ different mixing parameterizations. Furthermore we compare the results of experiment BR7 with the distribution simulated by the $1 / 3^{\circ}$ configuration (BR7h). Here annual means for the year 1990 are used to allow for a quantitative comparison to the CFC inventory estimates given by Smethie and Fine [2001]. For the qualitative comparison of tracer distributions, we use CFC-11 concentrations on an isopycnal surface corresponding to the tracer maximum in the uNADW, usually $\sigma_{0}=$ 27.78. All $4 / 3^{\circ}$ experiments use the constant timescale of 2 days for surface CFC restoring, since the analysis in section 3.2 has shown that this is an appropriate approximation of the "real" gas transfer velocity in our experiments.

[46] England and Holloway [1998] have shown that the introduction of an isopycnal mixing scheme created a diffusive eastward spreading of the NADW tracer tongue in their coarse-resolution model instead of a concentrated outflow within the DWBC as observed by Weiss et al. [1985]. Figure 4a shows the general shape of the tracer distribution in UNADW in our experiment with pure isopycnal mixing (BR5). From the Labrador Sea, the outflowing CFC signal spreads rather uniformly southward and eastward. Between the Grand Banks of Newfoundland and a latitude of $25^{\circ} \mathrm{N}$ there is no sign of a concentrated tracer outflow in the DWBC. Instead, the maximum CFC concentration at a given latitude can be found in the center of the western basin. This behavior is typical for non-eddy resolving ocean models and reflects their sluggish deep circulation which is in contrast to tracer observations that clearly show a CFC core associated with uNADW close to the North American continental shelf [e.g., Smethie, 1999].
However, it should be noted that the overestimation of the southward propagation in the eastern basin in our model is not as drastic as in the ISOP experiment of England and Holloway [1998]. Furthermore, our model is able to simulate a more concentrated tracer propagation south of $25^{\circ} \mathrm{N}$, where the deep flow from the eastern basin rejoins the DWBC. Both points could present evidence that at a resolution of about $1^{\circ}$ numerical models begin to realistically capture some features of the observed tracer distributions, but it is also possible that the very high horizontal background diffusivity used by England and Holloway [1998] (value of the $A_{h}$ coefficient between 15 and $75 \%$ of the along-isopycnal diffusivity compared to 10 to $40 \%$ in our experiments, depending on depth) is responsible for the far too diffusive CFC signal in their isopycnal mixing experiment.

[47] The introduction of the GM90 parameterization of eddy-induced tracer advection improves our simulation in some aspects (Figure 4b): The eastward outflow from the Labrador Sea is reduced, leading to a less intense CFC propagation in the eastern basin of the North Atlantic. The southernmost extension of a given isoline can now clearly be found in the western basin, whereas isolines had a much more zonal direction in the experiment without GM90. These improvements could be attributed to the fact that no horizontal background diffusivity is required in the GM90 case. To test this, we ran an experiment with the GM90 parameterization and included a background diffusivity of $10^{6} \mathrm{~cm}^{2} / \mathrm{s}$. This experiment (not shown here) showed only marginal differences to the pure GM90 run, indicating that the GM90 parameterization is solely responsible for the improvements.

[48] At the same time, the already sluggish DWBC in experiment BR5 has slowed down in the GM90 run (BR2), and the associated tracer signal cannot make its way around the Grand Banks into the subtropical Atlantic. The core of the CFC-11 maximum is not connected to a boundary current structure, but propagates southward in the interior of the basin. Also, the tracer tongue does not reach as far across the equator and into the South Atlantic as in experiment BR5. In contrast to England and Holloway [1998] who noticed a vertical deplacement of the uNADW tracer maximum because of the weaker and shallower meridional overturning in their GM experiment, the CFC maximum is at the same depth in both of our experiments, and there is no significant change in the maximum overturning rate $(17 \mathrm{~Sv})$.

[49] The effect of the GM90 parameterization to mimic the conversion of available potential energy to eddy kinetic energy by flattening isopycnal surfaces and modifying the tracer advection speed has important consequences for our simulated DWBC: Underneath the Gulf Stream, the slope of the isopycnal surfaces is so weak that it is not possible to reverse the flow direction with increasing depth (via thermal wind). Therefore, NADW outflowing from the subpolar North Atlantic to the south has to pass on the off-shore side of the Gulf Stream which leads to the tracer distribution described above. Tracer observations on meridional sections southwest of the Grand Banks [Smethie, 1993, 1999] show that in addition to the uNADW CFC maximum on the continental shelf, local maxima of lower concentration exist in the interior. These have been attributed to recirculation 

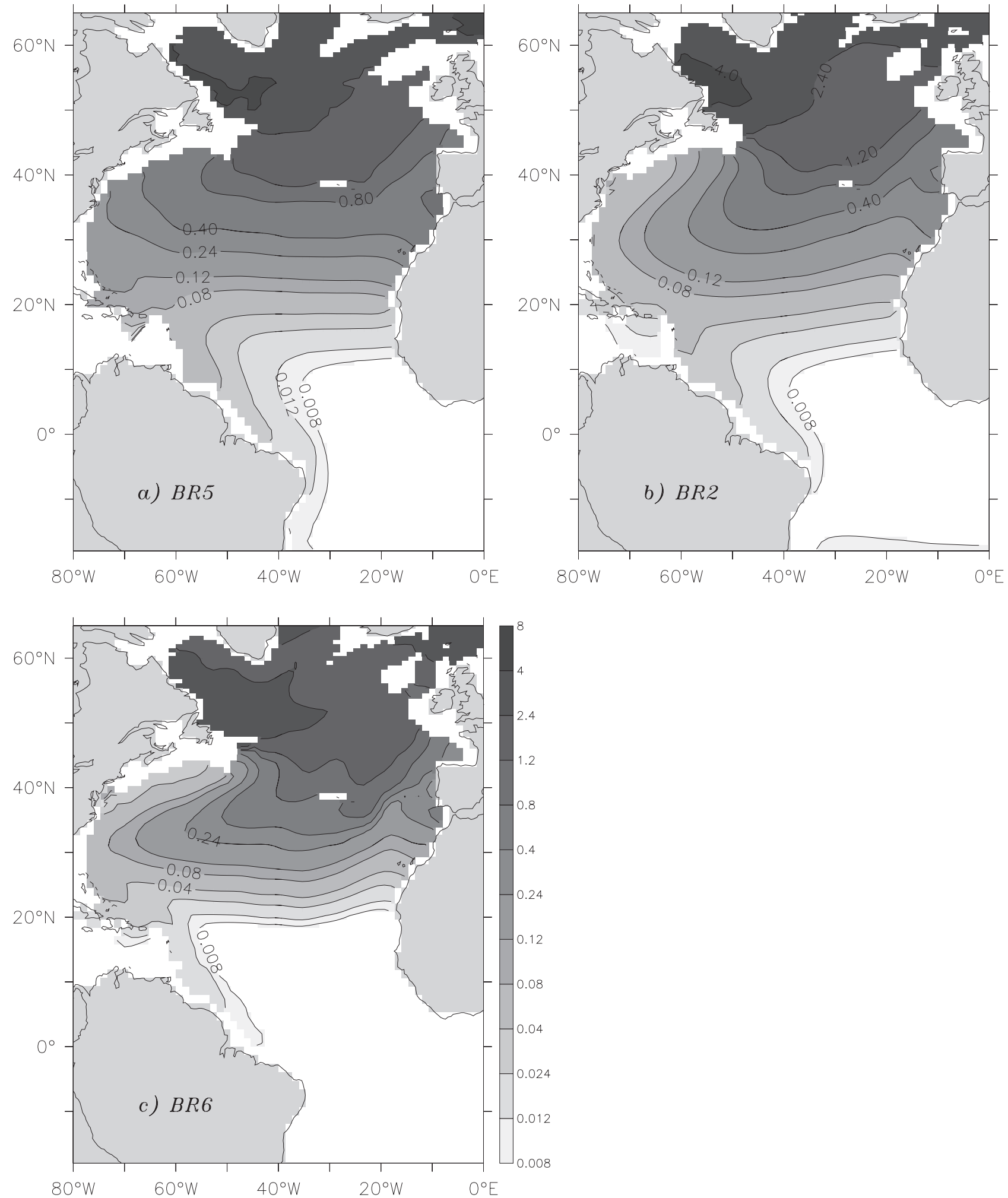

Figure 4. Annual mean CFC-11 concentration of year 1990 on the isopycnal surface $\sigma_{0}=27.78$, corresponding to the upper NADW niveau (in pmol/l). (a) Pure isopycnal mixing. (b) Isopycnal mixing including the GM90 parameterization. (c) Same as Figure 4a but with reduced thickness diffusivity.

cells in the DWBC, but they do not support the single interior maximum simulated in our GM90 experiment.

[50] The value of the thickness diffusivity coefficient used in BR2 is the same as in the study of Eden and
Willebrand [2001]; it varies with depth from $2000 \mathrm{~m}^{2} / \mathrm{s}$ in the thermocline to $500 \mathrm{~m}^{2} / \mathrm{s}$ in the deep ocean, but it does not include any horizontal dependence. In an attempt to provide a physically justified basis for the choice of the 

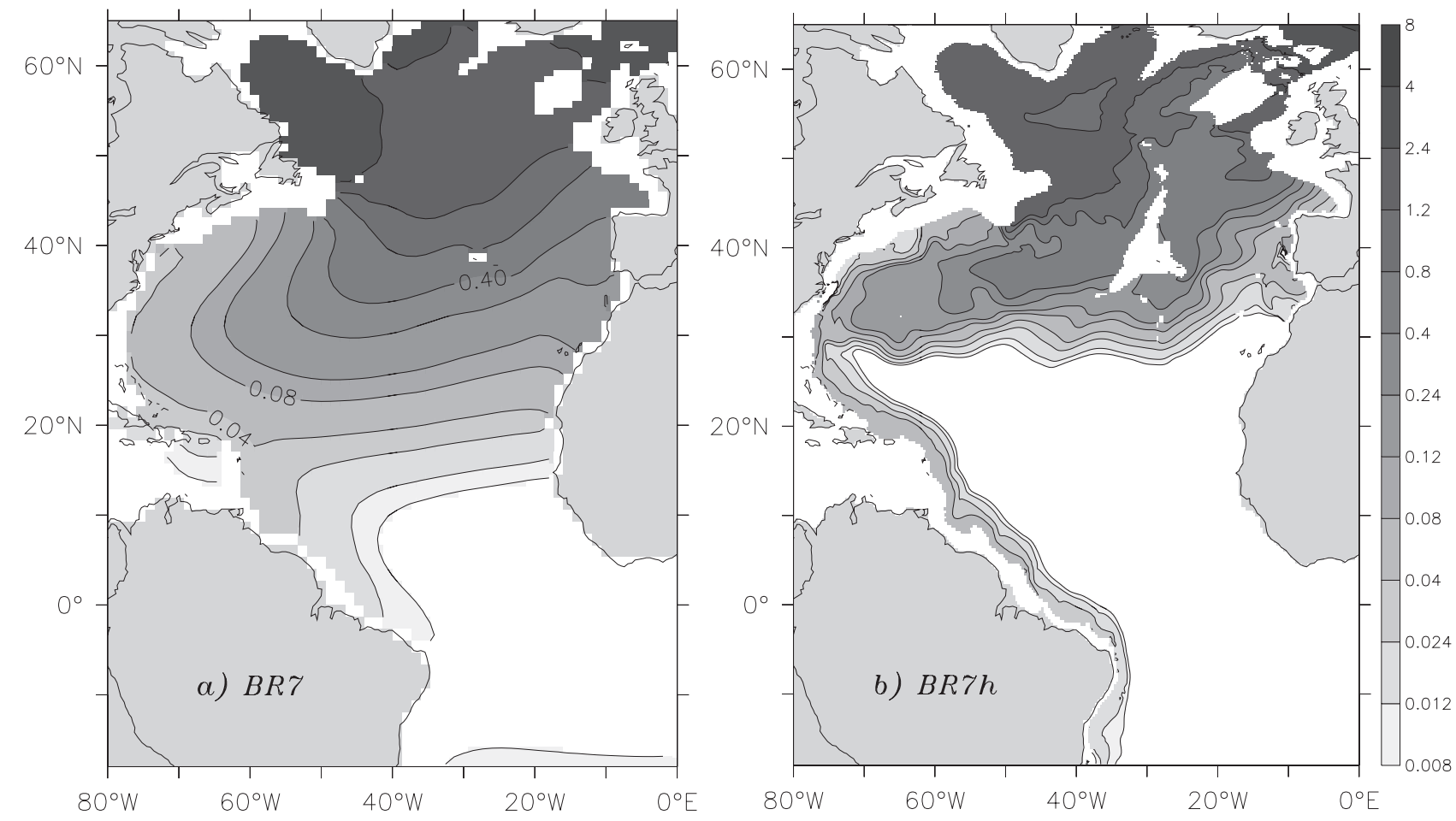

Figure 5. Same as in Figure 4 for (a) $4 / 3^{\circ}$ model $\left(\sigma_{0}=27.78\right)$ and (b) $1 / 3^{\circ}$ model $\left(\sigma_{0}=27.86\right)$.

thickness diffusivity coefficient, Visbeck et al. [1997] derived a formulation that depends on the Richardson number, the Coriolis parameter, and a length scale that measures the width of the "baroclinic zone." Since this formulation leads to strong spatial variations of the coefficient, one might argue that the value of the thickness diffusivity used in our experiment BR2 overestimates the mixing effect of baroclinic eddies in large parts of the ocean. Therefore we repeated case BR2 with a reduced thickness diffusivity (experiment BR6; maximum value in the thermocline $700 \mathrm{~m}^{2} / \mathrm{s}$ ).

[51] Figure 4c shows the resulting horizontal distribution of CFC-11 on the 27.78 isopycnal. Comparison with Figure $4 \mathrm{~b}$ shows that the Freon uptake in uNADW has been considerably reduced in the subpolar North Atlantic, which in turn leads to lower concentrations throughout the whole North Atlantic. The reason for this reduction lies in lower surface CFC-11 concentrations in the regions of tracer uptake, especially in the central Labrador Sea, where they are lower by $0.5-1 \mathrm{pmol} / 1$ in experiment BR6: The reduced mixing coefficient leads to stronger horizontal currents which in this experiment results in an enhanced advection of warm surface waters into the Labrador Sea, where the higher SST reduces the surface solubility and thereby the CFC-11 uptake. The tracer gradient in the interior of the subtropical basins is sharper in experiment BR6, and the tracer tongue reaching southwestward from the region between the Grand Banks and the Azores is narrower than it was in BR2, indicating that it has been produced by a more concentrated current structure. On the other hand, this signal still is located in the interior of the western basin instead of close to the continental shelf, and the propagation of the DWBC around the Grand Banks has not improved in comparison with experiment BR2. At the depth of the tracer maximum associated with DSOW the effect of the reduced thickness diffusivity is similar as far as the horizontal gradients are concerned, but it does not alter the southward extent of the DSOW tracer tongue significantly (not shown here). The CFC-11 inventory in NADW has been reduced by about $25 \%$ from experiment BR2 to BR6, and both the total inventory and the distribution of the inventory on the NADW components agree favorably with the numbers given by Smethie and Fine [2001] (see Table 2).

\subsubsection{Increased Horizontal Resolution}

[52] Figure 5 shows a comparison of two experiments that differ in their horizontal grid spacing (BR7 and BR7h, see Table 1), but have been run as similar as possible in all other aspects: both of them use isopycnal mixing including the GM90 scheme and a small horizontal background diffusivity ( $5 \%$ of the maximum thickness diffusivity in the $4 / 3^{\circ}$ case, $10 \%$ in the $1 / 3^{\circ}$ case), the BBL parameterization has been activated, and the forcing consisted of ECMWF mean fluxes with only the NCEP heat flux anomalies superimposed for the period $1958-1990$ (1958-1996 for the $4 / 3^{\circ}$ model). Both experiments employed a CFC surface restoring timescale of 7.43 days. The analysis in section 3.2 has shown that this results in an underestimation of the real gas transfer velocity as given by the Wanninkhof [1992] parameterization, but the computational demands of the $1 / 3^{\circ}$ configuration did not allow us to repeat the experiment with a different restoring timescale. Nevertheless, both experiments are perfectly comparable because of the identical timescale and can therefore be used both for qualitative and quantitative analyses of the effect of resolving a part of the mesoscale eddy spectrum on tracer distributions and inventories. $B \ddot{o}-$ ning et al. [2003] have shown that a simulation with a slightly different version of the $1 / 3^{\circ}$ configuration gave a CFC-11 distribution in the subpolar LSW that is in good agreement 
with observations [Rhein et al., 2002]. Therefore we assume that in spite of the quantitative discrepancies due to the too low piston velocity our experiment BR7h simulates the CFC uptake and spreading qualitatively right.

[53] The most obvious differences between the two panels in Figure 5 are the spatial extent of the tracer signal and the sharpness of the fronts. As stated by Redler and Dengg [1999], the CFC-11 distribution in UNADW is much more diffusive in the $4 / 3^{\circ}$ run (Figure $5 \mathrm{a}$ ) than a smoothing of the high-resolution results onto the coarse grid would suggest. In the subtropical and tropical Atlantic, the width and the speed of the DWBC differ strongly between the two configurations. In the $1 / 3^{\circ}$ case (Figure 5 b), the DWBC can be seen as a narrow boundary current off the American continent, and the southernmost tip of the tracer tongue has already reached $18^{\circ} \mathrm{S}$ (the southern boundary of the $1 / 3^{\circ}$ model), whereas it has just crossed the equator in the coarseresolution model. In the subpolar region, especially in the Labrador and Irminger Seas, CFC concentrations are lower in the eddy-permitting model which is a first indication that the simulated NADW tracer uptake depends on the grid resolution. In the boundary region between the subpolar and subtropical gyres, however, there are a number of similarities between the two cases: Even at higher resolution the simulated DWBC cannot follow the continental slope around the southern tip of the Grand Banks, but rather takes a path along the western slope of the Mid-Atlantic Ridge before it turns west at about $40^{\circ} \mathrm{N}$. Judging from the positions of the isolines between 0.24 and $0.8 \mathrm{pmol} / 1$, the spreading rate in this region is about the same in both experiments, and it is only south of about $35^{\circ} \mathrm{N}$ that the higher DWBC speed in the eddy-permitting case leaves a signature on the tracer distribution. The tracer signal associated with uNADW transport reaches the equator in 1985 in experiment BR7h, while it takes until 1987 in BR7. We note that, although still more diffusive and underestimating the DWBC speed, the tracer distribution in BR6 (reduced thickness diffusivity, Figure 4c) is qualitatively closer to the high-resolution result than the one from experiment BR7.

[54] The total subpolar CFC-11 inventory in NADW for 1990 is $18.3 \times 10^{6}$ moles for the coarse-resolution case and $11.6 \times 10^{6}$ moles for the eddy-permitting model (see Table 2). Although there may be some uncertainties in the tracer budget for the $1 / 3^{\circ}$ model because of the too dense Labrador Sea Water (discussed by Böning et al. [2003]), it is clear that a significant reduction of the simulated oceanic uptake of trace gases is brought about by the increased model resolution. The vertically integrated CFC-11 content (Figure 6), divided into a subtropical and a subpolar part by the isopycnal $\sigma_{0}=27.3$, shows that the overestimation of tracer uptake in the medium-resolution case does not occur everywhere. Regionally different mechanisms explain the differences between experiments BR7 and BR7h. As shown in Figures $6 \mathrm{c}$ and $6 \mathrm{~d}$, the medium-resolution model has a higher CFC content almost everywhere in the subpolar gyre. Highest differences can be found in the Labrador Sea where the content exceeds $8 \mu \mathrm{mol} / \mathrm{m}^{2}$ in BR7 compared to $5 \mu \mathrm{mol} / \mathrm{m}^{2}$ in BR7h. This difference can be attributed mainly to the larger horizontal extent of deep convection in BR7.

[55] The differences in the ventilation process can be illustrated by the rates of LSW formation (defined by the volume of newly ventilated LSW in winter). Averaged over the period 1958-1990, the LSW formation rate is $4.1 \mathrm{~Sv}$ in BR7 (varying between $0.3 \mathrm{~Sv}$ and $10.7 \mathrm{~Sv}$ ) whereas it is only $58 \%$ of this value in BR7h. The more vigorous dynamics in experiment BR7h lead to an enhanced advection of water originating from the North Atlantic Current into the Labrador Sea. Large parts of the Labrador Sea thus show a higher SST in BR7h than in BR7, which in turn leads to a lower surface CFC-11 concentration (Figure 7) because of the reduced solubility. Together with the reduction in the LSW formation rate, this results in a lower NADW CFC-11 inventory in BR7h.

[56] Integrated over the North Atlantic, the CFC inventory in deep waters amounts to $37.5 \times 10^{6}$ moles in BR7 compared to $32.4 \times 10^{6}$ moles in BR7h. Subtropical (thermocline) waters take up more CFC in the eddy-permitting model as clearly visible in Figures $6 \mathrm{a}$ and $6 \mathrm{~b}$. This translates into a total CFC-11 content above $\sigma_{0}=27.3$ of $16.9 \times 10^{6}$ moles in BR7 compared to $18.6 \times 10^{6}$ moles in $\mathrm{BR} 7 \mathrm{~h}$. Here higher resolution is a means to quantitatively improve the simulation of ventilation processes, as has been shown by Czeschel [2000]. The latter finding is in agreement with the results obtained by $\mathrm{C}$. Völker et al. (Anthropogenic $\mathrm{CO}_{2}$ uptake in the Atlantic studied with a basin-scale ocean general circulation model, submitted to $J$. Mar. Res., 2001) in a study of the oceanic uptake of anthropogenic $\mathrm{CO}_{2}$, and it thus underlines the utility of CFCs as proxy tracers for anthropogenic $\mathrm{CO}_{2}$.

[57] Since in BR7 we used the same thickness diffusivity as in BR2, one could argue that the BR7 inventory is an overestimation of the inventory that would have been simulated with a more appropriate thickness diffusivity coefficient. Assuming that the coefficient used in BR6 was in a more realistic range and given that the CFC inventory was reduced by about $25 \%$ from model case BR2 to BR6, the appropriate inventory for BR7 would then accordingly be $13.84 \times 10^{6}$ moles (in NADW). Thus, the coarse-resolution CFC-11 inventory would still be higher by more than $2 \times 10^{6}$ moles than the one simulated with the eddy-permitting model. This might have important implications for modeling studies of the ocean's role in the global carbon cycle and for climate change scenarios which, because of the long integration periods, have to rely on very coarse ocean models.

[58] We conclude our analysis with a comparison of the latitudinal distribution of CFC inventories in NADW from a number of medium-resolution and eddy-permitting model experiments. Figure 8 shows time series of the ratio of the subpolar CFC-11 inventory (integrated over the NADW density classes and over the region between $42^{\circ} \mathrm{N}$ and $65^{\circ} \mathrm{N}$ ) to the Atlantic CFC-11 inventory in NADW (integrated between $20^{\circ} \mathrm{S}$ and $65^{\circ} \mathrm{N}$ ). This measure gives an indication how fast and to which degree a tracer that enters the Atlantic in subpolar latitudes is exported to the subtropics and tropics in a given model, regardless of the absolute tracer content and the respective NADW pathways. Smethie and Fine [2001] estimated from nonsynoptic observations that as of $1990,65.4 \%$ of the NADW CFC11 inventory had remained in the region north of $42^{\circ} \mathrm{N}$.

[59] Starting from 1958, the subpolar part of the CFC inventory decreases gradually in all experiments, and the rate of decrease is roughly the same for all experiments 


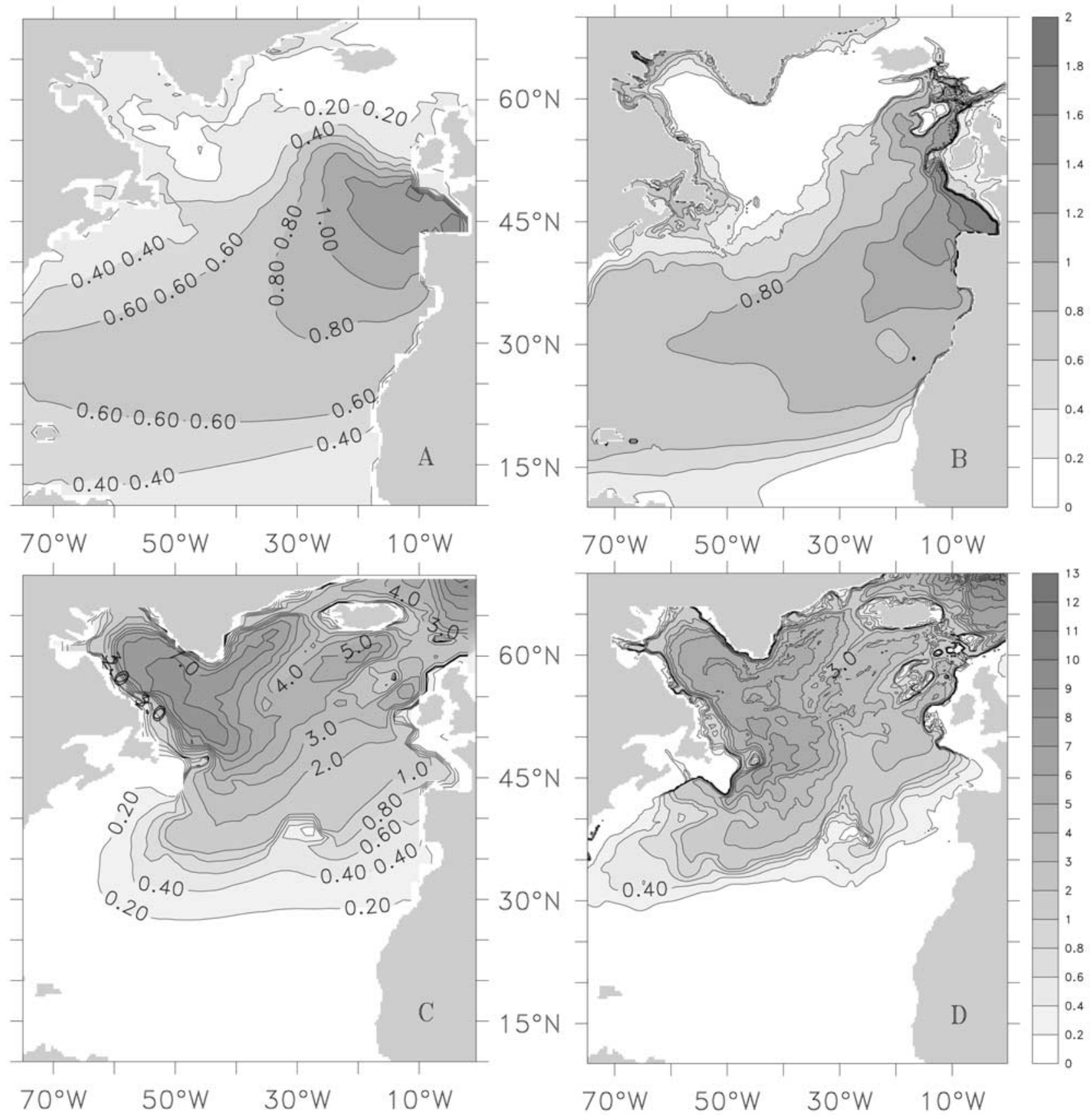

Figure 6. Vertically integrated annual mean CFC-11 content (in $\mu \mathrm{mol} / \mathrm{m}^{2}$ ) above the $\sigma_{0}=27.3$ isosurface for (a) our experiment BR7, (b) BR7h, and below the $\sigma_{0}=27.3$ isosurface for experiments (c) BR7 and (d) BR7h.

(interannual fluctuations of CFC uptake and export as well as their mechanisms are not the focus of this study and will be analyzed in a subsequent report). Throughout the whole period of nearly 40 years, all models agree to within $\pm 5 \%$ in their simulation of CFC export from the subpolar Atlantic, and in 1990 , between 80 and $86 \%$ of the CFC inventory have not left the region north of $42^{\circ} \mathrm{N}$.

\section{Discussion and Conclusions}

[60] A series of experiments with a numerical model of the Atlantic has been used to study formation processes of the different water mass components of NADW and the uptake of anthropogenic trace gases. To complement previous studies of this kind performed with models of rather coarse resolution, we employed a model with a horizontal resolution of $4 / 3^{\circ} \times 4 / 3^{\circ} \cos (\phi)$ encompassing the Atlantic in the latitudinal range $70^{\circ} \mathrm{N}$ to $70^{\circ} \mathrm{S}$. Sensitivity studies with respect to various mixing parameterizations are completed by a model with a 4-times higher resolution in both horizontal directions. A first comparison with observed CFC data showed that our model is well able to capture the most prominent features like the surface concentration, the transport of dense water masses from the Arctic Sea into 

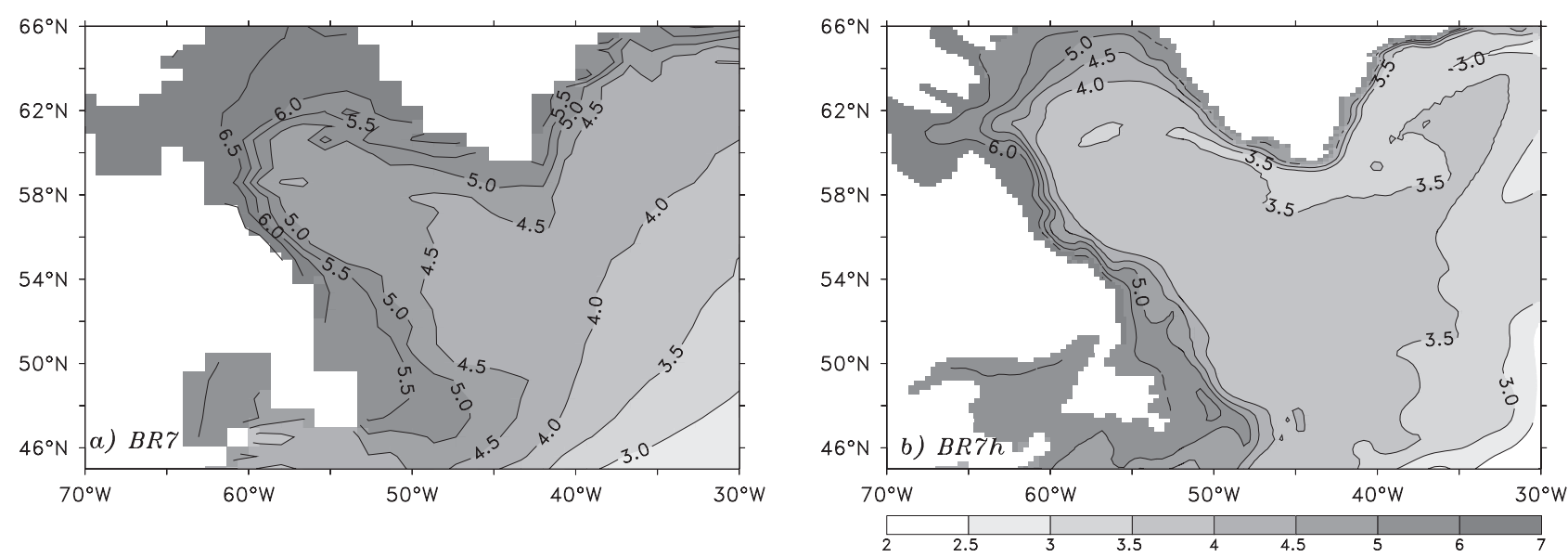

Figure 7. Surface CFC-11 concentration (in pmol/1) in the Labrador Sea. 1990 annual means from (a) experiment BR7 and (b) experiment BR7h (smoothed with a three-point window).

the subpolar North Atlantic, and the formation of NADW. We note that because of the closed northern boundary and the associated restoring zone our model is not able to simulate low-frequency (periods $>1$ year) fluctuations of the $\mathrm{T} / \mathrm{S}$ characteristics of the overflow water masses in the Nordic Seas. The CFC inventories in DSOW in experiments BR2 and BR6 show, however, that this does not inhibit a realistic simulation of tracer contents in the Atlantic.

[61] The present study has shown that model physics dominate the quality of a passive tracer simulation. The importance of including key physical processes (like the overflow of dense water masses, parameterized by a bottom boundary layer) has been highlighted. Moreover, we have shown that parameterizing or explicitly resolving a part of the mesoscale eddy spectrum has a quantitative effect on tracer inventories that is by far larger than the effect of details in the choice of the parameters governing the surface air-sea gas transfer. We examine the results of our experiments in the context of previous published model studies and observations.

[62] Assuming that the simulated surface temperature and salinity compare reasonably well with observations, the amount of CFC uptake by the ocean is determined solely by the representation of the gas transfer velocity. England et al. [1994] have already shown that keeping the surface CFC concentration at $100 \%$ saturation leads to fairly unrealistic results with respect to simulated CFC concentrations in the deep ocean. Furthermore, in their study it turned out to be of major importance to take into account the ice coverage during winter which inhibits the gas transfer from the atmosphere into the ocean. Despite the fact that our approach to include the effects of ice coverage (surface heat and CFC fluxes are zero during cooling phases if SST is below freezing point) is fairly simple, the close match between the observed and simulated CFC concentrations in subpolar latitudes on the $20^{\circ} \mathrm{W}$ section shows that this technique is sufficient to include the time-averaged effect of ice coverage for the type of ocean models used in this study.

[63] The comparison of the Wanninkhof [1992] parameterization with the approach of a constant piston velocity showed only marginal differences of $2.4 \%$ in the zonally averaged CFC-11 inventory. Similar experiments have been performed by England et al. [1994]. Since both the constant piston velocities and the wind speed data used in the Wanninkhof [1992] parameterization were different from the ones used in our study, it is not possible to compare the results quantitatively. Judging from the differences of CFC concentrations on a particular section in the South Atlantic shown by England et al. [1994, their Figure 9h], the integrated effect of the Wanninkhof [1992] parameterization seems to be greater (approximately 6\%) in their study. The higher differences found by England et al. [1994] might simply be due to the location of the section chosen for comparison, but from the present data one cannot exclude an influence of the model grid spacing: A coarse resolution model such as the one used by England et al. [1994] might be more sensitive to the gas transfer parameterization, because high wind speeds can induce an increase of the gas transfer velocity over a larger area.

[64] In the subpolar North Atlantic the model used by England et al. [1994, their Figure 10] shows almost no

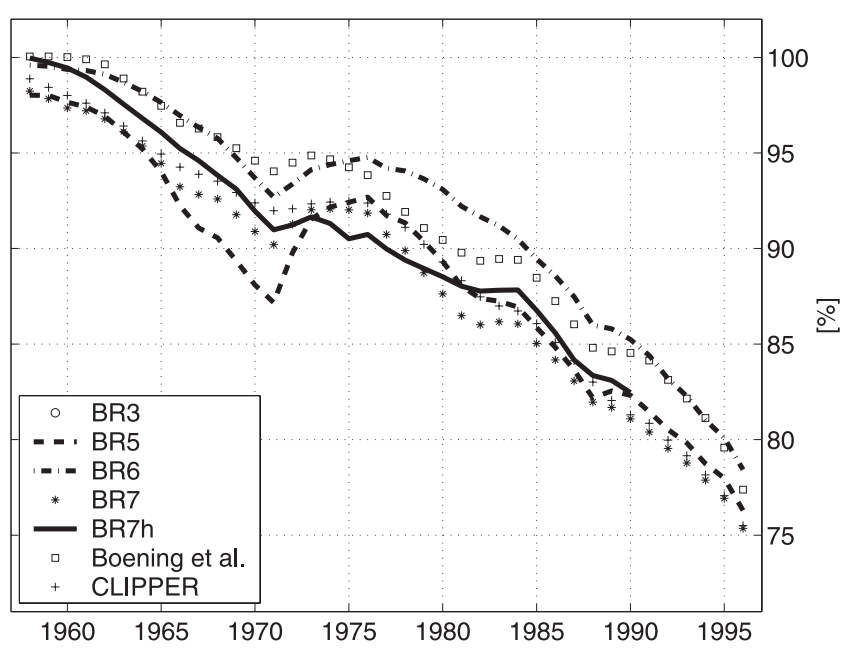

Figure 8. Time series of the relative subpolar CFC-11 inventories (see text for explanations). Also shown are the relative CFC-11 inventories from a $1^{\circ}$ simulation from the CLIPPER project [Beismann, 1999; Tréguier et al., 1999] and from a $1 / 3^{\circ}$ experiment described by Böning et al. [2003]. 
sensitivity to details in the formulation of the gas transfer parameterization. A possible reason for this is their underestimation of convection depths in the North Atlantic that inhibits the transfer of tracers taken up during convection to deeper water masses. As has been shown by Eden and Willebrand [2001], our model is able to simulate realistic convection depths. The more realistic simulation of the ventilation of the deep ocean increases the model's sensitivity to different gas transfer velocities, and the comparison between our experiments BR1 and BR2 has shown that it is necessary to capture the high values of $20 \mathrm{~cm} / \mathrm{h}$ that are obtained in the subpolar gyre during the winter season: With the lower value of $5.6 \mathrm{~cm} / \mathrm{h}$ (that had been chosen in experiment BR1 regardless of the higher average value of the gas transfer velocity obtained with the parameterization by Wanninkhof [1992]) it is not possible to simulate CFC concentrations that reach observed values.

[65] It remains to be clarified whether the use of a wind speed dependent parameterization as the one employed in this study [Wanninkhof, 1992] or those proposed by other authors [e.g., Wanninkhof and McGillis, 1999; Liss and Merlivat, 1986], Haine and Richards [1995] will show significant effects in models that resolve at least a part of the spatial spectrum of oceanic mesoscale activity as the one used in experiment BR7h.

[66] Once a reasonable value is chosen for parameterizing the gas uptake by the ocean the CFC content and the distribution in the water column depends more on the parameterization for subgrid-scale physics than on details of the piston velocities applied. As already stated by England and Maier-Reimer [2001] most if not all studies that used CFCs to assess model circulation and water mass formation in the North Atlantic identify problems with correctly representing NADW components.

[67] The most prominent feature is the lack of a deeper core of CFC within the DWBC representing the CFC signal in the DSOW. Applying the BBL according to Beckmann and Döscher [1997] is necessary in level models using grid resolutions comparable to our configuration in order to capture the overflow processes in a numerical simulation. While the total content of CFC in the NADW remains constant, with the aid of the BBL our model now produces a second deeper core of NADW and a CFC-11 inventory in DSOW that agrees with observational estimates. Nevertheless, the BBL alone is not sufficient to provide realistic results. The mixing scheme itself has to guarantee that the water masses carried within the BBL are not subject to explicit diffusion and mixing with surrounding water masses of different characteristics.

[68] Isopycnal mixing in combination with GM90 gives the most realistic results with respect to the distribution of NADW components in the DWBC provided that a BBL scheme is applied. The GM90 parameterization is necessary in our $4 / 3^{\circ}$ model in order to achieve a vertical distribution of the NADW tracer inventory that is in agreement with observations, but the choice of the thickness diffusivity coefficient strongly influences the absolute amount of CFC-11 taken up in the subpolar North Atlantic. In spite of this positive influence on the integral characteristics of our tracer simulations and although there are strong physical arguments for its use in medium-resolution ocean models [e.g., Böning et al., 1995], in our experiments the GM90 parameterization has an undesirable influence on the pathway of NADW flowing from the subpolar into the subtropical North Atlantic. A possible remedy for this could be the implementation of a spatially varying thickness diffusivity as proposed by Visbeck et al. [1997].

[69] We note furthermore that isopycnal mixing without the GM90 parameterization is not able to produce the deep tracer maximum associated with DSOW and leads to a considerable underestimation of the DSOW tracer inventory, even when combined with the BBL parameterization by Beckmann and Döscher [1997]. The reason for this unclear, and it is beyond the scope of this study to clarify whether this might be an effect of the horizontal background diffusivity that had to be employed in this experiment or of the choice of the BBL parameters, or a combination of the two.

[70] Models that differ in various computational and physical aspects produce significantly different CFC-11 inventories. However, if we compare the CFC-11 inventories of the subpolar North Atlantic relative to the total inventory, our experiments closely match each other. Furthermore, our relative inventories are in the same range as those calculated from data by Böning et al. [2003] and Beismann [1999]. The remarkable agreement in export rate and percentage between the experiments with different horizontal grid spacing illustrates the role non-eddy resolving models can play in studies of oceanic tracer uptake: If for a given problem only integrated quantities (e.g., like tracer inventories in latitudinal bands of several degrees width) and not the detailed pathways of a tracer in the ocean are of interest, medium-resolution models will give useful results and can trustfully be used in computational demanding studies that prohibit the use of finer grids, provided that eddy parameterizations have been carefully chosen in order to ensure quantitatively reliable results. The latter condition may require a "calibration" of the coarse-resolution model against observations or results of high-resolution experiments. Nevertheless from the point of view of this study, high resolution is required if the very details of the boundary currents have to be resolved. Despite the similarities noted above the increased horizontal resolution reduces the total uptake of CFC by $36 \%$. This may have important implications for modeling studies of the ocean's role in the global carbon cycle and for climate change scenarios which, because of the long integration periods have to rely on very coarse grid ocean models.

[71] The great discrepancy between the modeled relative distributions and the observational estimate by Smethie and Fine [2001], however, raises two further questions: First, all models might underestimate the real (but unknown) tracer export rate, even at high resolution. This would imply that the simulated DWBC is systematically too slow in numerical models and that even higher resolution is necessary in order to achieve realistic simulations. On the other hand, the data basis used by Smethie and Fine [2001] may be too sparse to calculate inventories over large regions, and the interpolation procedures as well as the assumptions that were necessary to produce a quasi-synoptic data set for 1990 from hydrographic observations from different years (1986 to 1992) may introduce systematic errors in inventory calculations. Further study is required to explain this discrepancy, and the availability of tracer inventories based on 
data that have been collected during WOCE in the 1990s will be very important in doing so.

[72] Acknowledgments. We greatly acknowledge the FLAME group, especially the work of Carsten Eden and Christian Dieterich for model development, and Ralf Döscher for providing the coding for the bottom boundary layer. One of the experiments has been realized while the first author was supported by a HSP III scholarship from the German Academic Exchange Service (DAAD). NCEP/NCAR reanalysis data were provided through the NOAA Climate Diagnostics Center (http//www.cdc.noaa.gov/). Scott Doney kindly provided the CFC data from the Malcolm Baldridge cruise. Work of Steve Hankin and his group at NOAA/PMEL is acknowledged for providing the FERRET plotting package. The John von Neumann Institute for Computing, Jülich, is acknowledged for providing access to their CRAY T3E-1200. Comments by Andreas Oschlies, Christoph Heinze, and an anonymous reviewer helped to improve the manuscript.

\section{References}

Barnier, B., L. Siefridt, and P. Marchesiello, Thermal forcing for a global ocean circulation model using a three-year climatology of ECMWF analyses, J. Mar. Syst., 6, 363-380, 1995.

Beckmann, A., and R. Döscher, A method for improved representation of dense water spreading over topography in geopotential-coordinate models, J. Phys. Oceanogr., 27, 581-591, 1997.

Beismann, J.-O., Etude des variations de la circulation thermohaline dans l'océan Atlantique par simulation de la circulation et de la distribution des chlorofluorométhanes, Ph.D. thesis, Univ. Joseph Fourier, Grenoble, France, 1999.

Böning, C., W. Holland, F. Bryan, G. Danabasoglu, and J. McWilliams, An overlooked problem in model simulations of the thermohaline circulation and heat transport in the Atlantic Ocean, J. Clim., 8, 515523, 1995.

Böning, C., M. Rhein, J. Dengg, and C. Dorow, Modeling CFC inventories and formation rates of Labrador Sea Water, Geophys. Res. Lett., 30, 1050, doi:10.1029/2002GL014855, 2003.

Boyer, T. P., and S. Levitus, Objective analyses of temperature and salinity for the world ocean on a 1/4 degree grid, NOAA Atlas NESDIS 11, U. S. Gov. Printing Office, Washington, D. C., 1997

Broecker, W. S., T. H. Peng, and T. Takahashi, A strategy for the use of bomb produced radiocarbon as a tracer for the transport of fossil fuel $\mathrm{CO}_{2}$ into the deep sea source region, Earth Planet. Sci. Lett., 49, 463-468, 1980.

Cox, M. D., Isopycnal diffusion in a z-coordinate model, Ocean Model., 74, $1-5,1987$.

Cummins, P. F., G. Holloway, and A. E. Gargett, Sensitivity of the GFDL ocean general circulation model to a parameterization of vertical diffusion, J. Phys. Oceanogr., 20, 817-830, 1990.

Czeschel, L., Modelluntersuchungen zur Ventilation der Hauptsprungschicht im subtropischen Nordatlantik, Master's thesis, Inst. für Meereskunde an der Univ. Kiel, Kiel, Germany, 2000.

Dengg, J., C. Böning, U. Ernst, R. Redler, and A. Beckmann, Effects of an improved model representation of overflow water on the subpolar north atlantic, Int. WOCE Newsl., 37, 10-15, 1999.

Dickson, R. R., and J. Brown, The production of North Atlantic Deep Water: Sources, rates, and pathways, J. Geophys. Res., 99, 12,319$12,341,1994$

Dickson, R., J. Lazier, J. Meinke, and P. Rhines, Long-term coordinated changes in the convective activity of the North Atlantic, in Decadal Climate Variability, edited by D. L. T. Anderson and J. Willebrand, pp. 211-262, Springer Verlag, New York, 1996.

Doney, S., J. Bullister, and R. Wanninkhof, Climatic variability in upper ocean ventilation rates diagnosed using chlorofluorocarbons, Geophys. Res. Lett., 25, 1399-1402, 1998.

Döscher, R., and A. Beckmann, Effects of a bottom boundary layer parameterization in a coarse-resolution model of the North Atlantic Ocean J. Atmos. Oceanic Technol., 17, 698-707, 2000.

Dutay, J.-C., et al., Evaluation of ocean model ventilation with CFC-11: Comparison of 13 global ocean models, Ocean Model., 4, 89-120, 2002.

Eden, C., and J. Willebrand, Mechanism of interannual to decadal variability of the North Atlantic circulation, J. Clim., 14, 2266-2280, 2001

England, M. H., Using chlorofluorocarbons to assess ocean climate models, Geophys. Res. Lett., 22, 3051-3054, 1995.

England, M. H., and A. C. Hirst, Chlorofluorocarbon uptake in a world ocean Model: 2. Sensitivity to surface thermohaline forcing and subsurface mixing parameterizations, J. Geophys. Res., 102, 15,709-15,731, 1997.
England, M., and G. Holloway, Simulations of CFC content and water mass age in the deep North Atlantic, J. Geophys. Res., 103, 15,885-15,901, 1998.

England, M., and E. Maier-Reimer, Using chemical tracers to assess ocean models, Rev. Geophys., 39, 29-70, 2001

England, M. H., V. Garcon, and J.-F. Minster, Chlorofluorocarbon uptake in a world ocean model: 1. Sensitivity to the surface gas forcing, J. Geophys. Res., 99, 25,215-25,233, 1994.

Gent, P. R., and J. C. McWilliams, Isopycnal mixing in ocean circulation models, J. Phys. Oceanogr., 20, 150-155, 1990.

Girton, J., T. Sanford, and R. Käse, Synoptic sections of the Denmark Strait Overflow, Geophys. Res. Lett., 28, 1619-1622, 2001.

Haine, T., and K. Richards, The influence of the seasonal mixed layer on oceanic uptake of CFCs, J. Geophys. Res., 100, 10,727-10,744, 1995.

Haney, R. L., Surface thermal boundary conditions for ocean circulation models, J. Phys. Oceanogr., 1, 241-248, 1971.

Heinze, C., E. Maier-Reimer, and P. Schlosser, Transient tracers in a global OGCM: Source functions and simulated distributions, J. Geophys. Res., 103, 15,903-15,922, 1998 .

Kalnay, E., et al., The NCEP/NCAR 40-years reanalysis project, Bull. Am. Meteorol. Soc., 77, 437-471, 1996.

Käse, R., and A. Oschlies, Flow through Denmark Strait, J. Geophys. Res., 105, 28,527-28,546, 2000.

Körtzinger, A., M. Rhein, and L. Mintrop, Anthropogenic $\mathrm{CO}_{2}$ and CFCs in the North Atlantic Ocean: A comparison of man-made tracers, Geophys. Res. Lett., 26, 2065-2068, 1999.

Kröger, J., Mechanismen meridionaler Transportprozesse im tropischen Atlantik, Ph.D thesis, Univ. Kiel, Kiel, Germany, 2001.

Levitus, S., R. Burgett, and T. P. Boyer, World Ocean Atlas 1994 vol. 3, Salinity, NOAA Atlas NESDIS 3, 111 pp., Natl. Oceanic and Atmos. Admin., Silver Spring, Md., 1994.

Liss, P., and L. Merlivat, Air-sea gas exchange rates: Introduction and synthesis, in The Role of Air-Sea Exchange in Geochemical Cycling, edited by P. Buat-Ménard, pp. 113-127, D. Reidel, Norwell, Mass., 1986.

National Geophysical Data Center, Digital relief of the surface of the Earth, Data Announce. 88-MGG-02, Boulder, Colo., 1988.

Pacanowski, R. C., MOM 2 Documentation, user's guide and reference manual, Tech. Rep. 3, GFDL Ocean Group, Princeton, N. J., 1995.

Rahmstorf, S., J. Marotzke, and J. Willebrand, Stability of the thermohaline circulation, in The Warmwatersphere of the North Atlantic Ocean, edited by W. Krauss, pp. 129-157, Gebr. Bornträger, Stuttgart, Germany, 1996

Redi, M. H., Oceanic isopycnal mixing by coordinate rotation, J. Phys. Oceanogr., 12, 1154-1158, 1982.

Redler, R., and J. Dengg, Spreading of CFCs in numerical models of differing resolution, Int. WOCE Newsl., 35, 12-14, 1999.

Rhein, M., The Deep Western Boundary Current: Tracers and velocities, Deep Sea Res., Part I, 41, 263-281, 1994.

Rhein, M., J. Fischer, W. Smethie, D. Smythe-Wright, R. Weiss, C. Mertens, D.-H. Min, U. Fleischmann, and A. Putzka, Labrador Sea Water: Pathways, CFC-inventory and formation rates, J. Phys. Oceanogr., 32, $648-665,2002$

Saunders, P. M., The flux of dense cold overflow water southeast of Iceland, J. Phys. Oceanogr., 26, 85-95, 1996.

Siefridt, L., Validation des données ERS-1 et des flux de surface du CEPMMT dans le contexte de la modélisation des circulations océaniques á l'échelle d'un bassin, Ph.D thesis, Univ. Joseph Fourier, Grenoble, France, 1994

Smethie, W., Jr., Tracing the thermohaline circulation in the western North Atlantic using chlorofluorocarbons, Prog. Oceanogr., 31, $51-$ 99, 1993.

Smethie, W., Jr., Meridional distribution of CFCs in the western subtropical Atlantic Ocean, Int. WOCE Newsl., 37, 15-17, 1999.

Smethie, W., Jr., and R. Fine, Rates of North Atlantic Deep Water formation calculated from chlorofluorocarbon inventories, Deep Sea Res., 48, 189215,2001

Sterl, A., and A. Kattenberg, Embedding a mixed layer model into an ocean general circulation model of the Atlantic: The importance of surface mixing for heat flux and temperature, J. Geophys. Res., 99, 14,13914,157, 1994.

Stevens, D. P., The open boundary condition in the United Kingdom FineResolution Arctic Model, J. Phys. Oceanogr., 21, 1494-1499, 1991

Tréguier, A.-M., et al., The CLIPPER project: High resolution modelling of the Atlantic, Int. WOCE Newsl., 36, 3-5, 1999.

Visbeck, M., J. Marshall, T. Haine, and M. Spall, Specification of eddy transfer coefficients in coarse-resolution ocean circulation models, J. Phys. Oceanogr., 27, 381-402, 1997.

Wanninkhof, R., Relationship between wind speed and gas exchange over the ocean, J. Geophys. Res., 97, 7373-7382, 1992. 
Wanninkhof, R., and W. R. McGillis, A cubic relationship between air-sea $\mathrm{CO}_{2}$ exchange and wind speed, Geophys. Res. Lett., 26, 1889-1892, 1999.

Weaver, A. J., and T. M. C. Hughes, On the incompatibility of ocean and atmosphere models and the need of flux adjustments, Clim. Dyn., 12, $141-170,1996$.

Weiss, R., J. Bullister, R. Gammon, and M. Warner, Atmospheric chlorofluoromethanes in the deep equatorial Atlantic, Nature, 314, 608-610, 1985.

Willebrand, J., B. Barnier, C. Böning, C. Dieterich, P. Killworth, C. L. Provost, Y. Jia, J.-M. Molines, and A. L. New, Circulation characteristics in three eddy-permitting models of the North Atlantic, Prog. Oceanogr. $48,123-161,2001$

J.-O. Beismann, Institut für Meereskunde an der Universität Kiel, Düsternbrooker Weg 20, 24105 Kiel, Germany. (jobeismann@ifm.uni-kiel. de)

R. Redler, C\&C Research Laboratories, NEC Europe Ltd., 53757 Sankt Augustin, Germany. (rene.redler@ccrl-nece.de) 